\title{
Exploring learning-oriented assessment processes
}

Carless, D. (2014). Exploring learning-oriented assessment processes. Higher Education, DOI 10.1007/s10734-014-9816-z

\begin{abstract}
This paper proposes a model of learning-oriented assessment to inform assessment theory and practice. The model focuses on three interrelated processes: the assessment tasks which students undertake; students' development of self-evaluative capacities; and student engagement with feedback. These three strands are explored through the analysis of assessment practice in context. The research method involves in-depth classroom observations of five recipients of awards for teaching excellence across multiple disciplines; and semi-structured interviews with these teachers and a sample of their students. Findings highlight assessment tasks promoting thinking and practicing in the discipline; the use of critical reviews to develop student understandings of quality work; and 'same day feedback' to promote timely dialogues with students. The coherence of the model is discussed and some areas for further exploration are suggested.
\end{abstract}

Keywords: learning-oriented assessment; assessment task design; student selfevaluation; engagement with feedback

\section{Introduction}

The theory and practice of student assessment in higher education has generated a lot of debate over the last twenty years or so. It is probably fair to say that there have been a number of positive developments during that time in promoting assessment for learning: more varied assessment tasks than merely a diet of final examinations; greater transparency in assessment criteria and strategies for promoting engagement with them; and a growing awareness of the importance, and the challenges, of developing effective feedback processes. There remain, however, various concerns about assessment and a recent paper in this journal describes a lack of sophistication in assessment practice and limited incentives to innovate, especially in contexts where research is prioritized over teaching (Norton, Norton and Shannon, 2013). 
There is now widespread acceptance for approaches to assessment focused on promoting and enhancing student learning (Sambell, McDowell and Montgomery, 2013). A key aspect of such approaches is the extent to which assessment tasks are conducive to stimulating appropriate student learning approaches. A fundamental challenge for teacher management of assessment, however, is that it has to do 'double duty’ (Boud, 2000), serving varied and sometimes potentially competing functions. Assessments have to encompass formative assessment for learning and summative assessment for certification; they have to focus on the immediate task and equipping students for lifelong learning; and they have to attend to the learning process and the substantive content domain (Boud, 2000). Many teachers in higher education perceive that they lack individual autonomy and find themselves pulled in different directions by assessment purposes other than facilitating student learning (James, 2014). Effective assessment practice should focus on enhancing student learning processes, but needs to be informed by the awareness that assessments do double duty.

In this paper, I draw on the analysis of assessment practices in context to develop three interrelated contributions. The first is to present and discuss a model of learningoriented assessment. Second, I present data from case studies of five recipients of teaching awards to provide some illustrations of how learning-oriented assessment processes are implemented in undergraduate education (see Carless, 2015, for a fuller analysis). Third, I probe the implications for the model in light of the findings and suggest some areas for further research. The overall aim of the paper is to explore investigate learning-oriented assessment processes and discuss implications for theory and practice.

\section{Framing the study through learning-oriented assessment}

Learning-oriented assessment is defined as assessment where a primary focus is on the potential to develop productive student learning processes. In particular, the 'right kind' of summative assessment can be fruitful in stimulating appropriate student learning dispositions and behaviors. Summative assessment can be learning-oriented when, for example, it encourages deep rather than surface approaches to learning and when it promotes a high level of cognitive engagement consistently over the duration of a module. The processes of working towards well-designed summative assessment 
can also afford opportunities for formative assessment strategies, such as peer feedback, student self-evaluation and related teacher feedback.

Learning-oriented assessment has hitherto attracted some modest attention in the literature (Carless, 2007; Hernandez, 2012), but has not yet been conceptualized or explored in detail. I propose in figure 1, three simple but hopefully powerful interlocking principles of an approach to assessment predicated on the development of student learning processes. The aim of the model is to capture the core elements of a learning-oriented assessment approach and indicate their inter-relationships. The three principles are developed from synthesizing and reformulating key literature on assessment for learning in higher education (e.g. Boud and Falchikov, 2007; Gibbs, 2006; Sadler, 2010; Sambell et al., 2013).

The apex of the model is represented by the assessment tasks which students are undertaking: key drivers of their efforts and learning approaches. Conceptualizing the nature of assessment task design and implementation could take various forms. For the purposes of this paper, I frame the discussion of learning-oriented assessment task design through the lens of ways of thinking and practicing (WTP) in the discipline (McCune and Hounsell, 2005) because it seems to me to be a particularly useful way of encapsulating some of the key issues around the development of quality undergraduate student learning in context.

Figure 1. A model of learning-oriented assessment

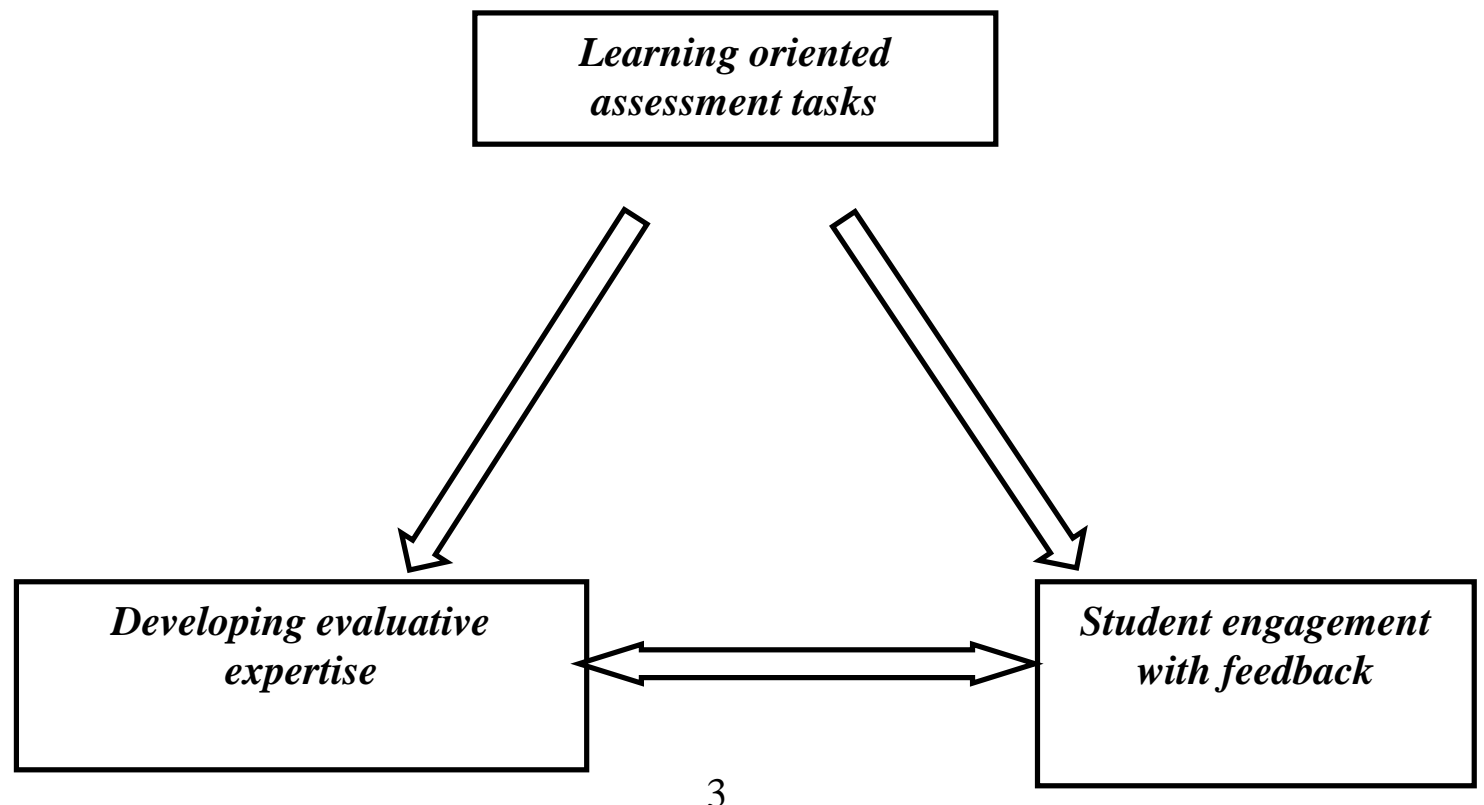


From a study of undergraduate courses in the biosciences, McCune and Hounsell (2005) suggest that high quality learning relates to students developing an evolving grasp of WTP in the subject. They describe WTP as denoting the richness, depth and breadth of what students might learn through engagement with a given subject area in a specific context, for example, coming to terms with particular disciplinary forms of discourse, values or ways of acting (McCune and Hounsell, 2005). WTP could also encompass an evolving familiarity with the conventions of scholarly communication within the discipline and the relevant professional community (Anderson and Hounsell, 2007). A major means of supporting the development of WTP is by engaging with and assessing 'real-life' problems, contextualized within specific disciplinary situations what is sometimes referred to as authenticity in assessment.

Turning now to the other two strands of the model, learning-oriented assessment task design is supported by the interconnected elements (illustrated at the bottom of figure 1 by inverted arrows) of evaluative expertise and engagement with feedback. Evaluative expertise on the left of the figure represents the evolving ability of students to engage with quality criteria, develop their self-evaluative capacities and make informed judgments about their own work, and that of others. Evaluative expertise is critical for student learning because to monitor and improve their learning, students need to know what quality performance involves and entails (Sadler, 1989). A crucial role of the teacher is to assist students in developing this capability in discerning quality and making complex judgments (Sadler, 2010). Developing assessment for informing judgment involves exposure to models and opportunities for practice (Boud and Falchikov, 2007).

Feedback is both a core aspect of improvement and something which research evidence indicates is difficult to manage effectively (Evans, 2013). For students to engage effectively with feedback (the right hand side of the figure), they need to develop a conception of quality which begins to approach that of the teacher (Sadler, 2010). They need this evolving capacity in order to facilitate the decoding and uptake of feedback messages which can often seem cryptic or opaque. The feedback strand of 
the learning-oriented assessment model places emphasis on student engagement with feedback. It is what the students can do with feedback, rather than how the teacher provides it, which is crucial (Boud and Molloy, 2013). There are, for example, challenges in relation to timing and modes of feedback; student understanding and uptake of feedback; and student affective responses (Evans, 2013). Current thinking suggests that the key purpose of feedback is to support students in developing their self-regulative capacities (Nicol and Macfarlane-Dick, 2006); and feedback needs to be re-engineered to encourage dialogues of different forms: peer feedback; internal feedback to the self; as well as external feedback from the teacher (Nicol, 2010).

The two arrows leading from the top to the bottom of the figure suggest that the nature of the assessment task or tasks impact on prospects for the development of evaluative expertise and engagement with feedback. Task-type is one salient issue, for example, 'on-display assignments', such as oral presentations or posters in which work is openly evident to peers rather than just privately submitted to tutors (Hounsell, 2003) provide opportunities for student appreciation of quality and associated development of evaluative expertise. The number and sequencing of tasks are another factor, for example, multi-stage assignments tend to provide more opportunities for student engagement with feedback than a single end-of-semester task.

To sum up, I have framed the discussion around three elements of a model of learning-oriented assessment: task design prioritizing assessing WTP in situations which mirror real-life uses of the discipline; the development of student evaluative expertise; and student engagement with feedback. The unified nature of the model suggests that task design should set up possibilities for the other two strands; and that there is interplay and potential overlap between students' development of evaluative expertise and their engagement with feedback. The model does not seek to measure student learning outcomes; instead it suggests three important precursors for the kind of learning processes which are likely to stimulate student engagement.

\section{Method}

The research is framed around the following questions: 
How is learning-oriented assessment implemented by selected award-winning teachers?

What are the teachers and students perceptions of the main learning-oriented assessment issues?

\section{Participants}

The teacher participants from an international research intensive university had all received internal awards for teaching excellence. Candidates for these awards are expected to demonstrate excellence in: teaching and engagement with student learning; curriculum design and innovation; and the scholarship of teaching (Prosser, 2013). A proposition underlying the choice of sample was that award-winning teachers might carry out learning and assessment practices which engage students and cast light on learning-oriented assessment processes. This was to be explored via indepth qualitative data collection and analysis of a small purposefully selected sample of teachers.

I began the research process by carrying out an exploratory case study of an awardwinning teacher from the Faculty of Business whose participation in a previous interview study (Carless et al., 2011) had evidenced innovative practices relevant to the research focus. This case formed the prototype for extending the study across additional disciplines so as to allow contextualization of insights in different subjects. Based on an overview of award-winning teachers in the university, I contacted potential participants and subsequent case studies focused on teachers of the following subjects: Architecture, Geology, History and Law.

The teachers were involved in undergraduate and postgraduate teaching, and doctoral supervision. After they agreed to participate, I negotiated with them a suitable undergraduate class to observe bearing in mind the aims of the research. Student participants were undergraduates enrolled in the selected courses taught by the awardwinners. In the process of observations, my co-researcher and I interacted with a range of students and invited a sample of them to participate in semi-structured interviews.

\section{$\underline{\text { Data collection }}$}


The study sought to understand how teachers implemented and students experienced assessment in the modules under investigation. It did not aim to measure student achievement, instead it sought to explore the processes in which students were involved and their perceptions of issues arising. In line with this orientation, the principal means of data collection were classroom observations and interviews. I was assisted by a co-researcher, a recent doctoral graduate specializing in qualitative research methods similar to those adopted in the study.

The main purposes of classroom observations were to develop an understanding of how classroom processes unfolded, particularly in relation to aspects relevant to the model of learning-oriented assessment. Classes were of two hours duration in Geology, History and Law; three hours in Business; and in Architecture studio activities were open-ended and did not follow a set time schedule. Six to ten sessions per teacher were observed, totaling 39 sessions across the five teachers or 92 hours of classroom observations. Detailed field notes were collected to describe classroom processes; develop provisional insights into issues relevant to the research focus; and identify issues for follow-up through interviews.

I carried out two main formal semi-structured interviews with the teachers: one at the outset of the study to understand their views on learning-oriented assessment issues and how teaching and assessment were approached in the courses; and the other to explore issues arising from the observations and the student data. Additional shorter interviews and/or follow-up e-mails were also used to collect their feedback on my provisional analysis.

Students from each of the classes were interviewed in order to gauge their perceptions of the learning-oriented assessment processes in the modules under discussion. I carried out some interviews myself whereas my co-researcher conducted the majority. Interviews focused on the relevant learning-oriented assessment issues arising in a particular course. Students were usually interviewed once for about half an hour, although longer interactions were common and a number of students were interviewed twice when the pertinent issues were significant over a sustained period of time. Overall, 90 interviews with 54 students were carried out and these were 
evenly spread across the five disciplines. All teacher and student interviews were recorded, transcribed verbatim and analyzed as per the procedures described below.

\section{Data analysis}

The observational and interview data were assigned codes which represented my interpretation of their main essence. The coded data were organized thematically around the three main concepts established a priori by adopting a learning-oriented assessment perspective. Case reports were developed for each of the five cases, including the multiple elements of classroom observational data, teacher and student perceptions.

For the purposes of this paper, data reduction and selection of examples from the case reports are a central move. My aim is not to provide a comprehensive analysis of a case but to present one example from three different cases which illustrate the relevant feature of the model of learning-oriented assessment. Selection of quotations seeks to present a balanced view of the evidence from the wider dataset.

The trustworthiness of interpretations was mainly developed through the following strategies: triangulation between observational data, teacher interviews and student interviews; prolonged engagement with the participants in the classes under discussion; and data collection and interpretation operating in tandem. I also carried out extensive member checking whereby the informants commented on drafts of the case studies pertaining to their teaching and I made modifications based on their clarifications. Peer reviews by both assessment specialists and scholars belonging to the relevant disciplines were also carried out. The involvement of two researchers was also particularly useful in that I presented issues to my co-researcher and made revisions, or reflected further, based on her comments.

\section{Findings}

The findings are divided into three main sections which address the corresponding component of the learning-oriented assessment model. In each sub-section, I begin with a brief general overview across cases and then discuss in detail a key feature from a particular case. 
Assessment task design and implementation

Task design across the cases involved different elements and emphases. The Architecture case involved continuous assessment of designs for a village house which were collected into a cumulative portfolio. In Geology, there was assessed laboratory work on rocks and minerals; a group project on a chosen novel problem; and a final exam. In Business, there was a written assignment based on a business case; oral presentations of product ideas; and a participation grade involving both oral classroom and written online contributions. The Law case involved traditional tests and exams as well as a portfolio-based reflective media diary identifying and analyzing legal issues from local newspaper reports. The History case is chosen for discussion in detail because it exemplifies prominent features of the design and implementation of learning-oriented assessment tasks.

Making History is a first year foundation course taken by a diverse cohort of 110 students from a variety of disciplines, taught by Marty (all names are pseudonyms). The main intended learning outcomes are for students to develop their abilities to: engage critically with representations of the past; analyze and use evidence to construct historical accounts; critically interpret interconnections between the past and the present; and reflect upon the value of historical awareness.

There are multiple assessment elements for the course. The first task is a fieldwork report of 1000 words which involves a choice between a Museum visit (to a local Museum of the student's own choice) or a Scavenger Hunt (an internet-based simulation in which students visit local landmarks examining historically-based clues and artifacts). The teacher explains some of the thinking behind these tasks in the following quotation:

It's important to get them out of the classroom into the context so that they can see ways in which people may look at the past ... They go into the museum and are asked to critique the space. They are provided with a list of questions as a framework so that they are not simply passively accepting what there is to see. There may be more than one version of a story and competing discourses; some of the students are attuned to this, whereas others are not. 
In Marty's views, I see a focus on providing tasks which relate to what it is to be a historian: involvement in critique, contestation, competing discourses and the meaning of the past.

There is also continuous assessment: $30 \%$ of the course grade involves assessed participation (15\% for participation in the weekly tutorials); and $15 \%$ for a weekly personal response task entitled 'one sentence response'. This latter task requires students to complete during the weekly lecture, a short handwritten personal response of about 20-30 words to an issue which is the focus of the next class. Two examples of these one sentence response tasks are:

- What are the essential qualities of a good museum?

- How might thinking historically be able to help us realize a better future?

Aspects of the teacher rationale for this exercise are addressed in the following quotation:

I want to assess their learning experience during classroom time and provide an incentive for attendance. I am a firm believer in the value of short written exercises. I think it is a great way of honing their communication skills; after all we live in an age of Twitter and students rarely have call to write long research pieces.

He explained that originally he had conceived it as partly a convenient way of taking the class attendance (an institutional requirement). Later, he saw it more as a way of encouraging student participation; giving students a voice in the class; and informing his teaching by helping him understand students' prior understandings and experiences.

The final assignment is an individual project counting 40\% (10\% for a draft and 30\% for the final submission). This is a 3000 word piece of writing, although it can alternatively be presented in the form of a podcast, wiki or other use of technology. Students can choose from a list of topics or propose one of their own. The teacher spoke about the project in the following terms:

I try as far as possible to get them to generate the materials and then to analyze and critique. It's an attempt to give students an opportunity to showcase their 
abilities; master the discourse of history; see the past is alive and that participants are re-shaping it; and see themselves as historians.

I interpret this quotation as reiterating an intention to involve students in ways of thinking and practicing as historians.

Space precludes a detailed discussion of student views on the different assessment items. Instead, I highlight a representative selection of their overall views on the assessment approach:

The assessment provides real flexibility. You have activities to do and you are graded on them. Overall, I would say it is good.

I quite like the assessment approach because I can take the initiative to learn. The teacher encouraged us to raise our own opinions and search for evidence to support them.

The assessments for this module motivate you to learn more. If you want to get an outstanding overall result, you have to work hard on each task.

The assignments of this course require us to do some field research and independent thinking. It was hard work but it gave me a sense of achievement.

The assessment is open and flexible and you can have your own ideas. What I have gained is regeneration of ways of thinking, understanding issues from different angles.

These comments bring out some of the student perceptions of features of the assessment: flexibility; opportunities to take the initiative; motivation and independent thinking. The final student comment is suggestive of the kind of learning outcomes which are being developed: thinking skills and alternative ways of understanding.

In sum, the design of the assessment was that students were involved in multiple tasks rather than a single end of semester assignment. The content involved the teacher providing tasks focused on participation in the discipline, mirroring historical ways of thinking. 


\section{Developing student evaluative expertise}

In different ways, all of the five teachers in the study communicated performance criteria to students and endeavored to exemplify some of the elements of quality assignments. The Geology teacher explicitly explained the qualities of a good group project in his introduction to that particular task. The History teacher held an optional additional workshop to try to illustrate strategies for tackling the project assignment, shared a good sample assignment and added some related commentary. The Law teacher posted annotated exemplars of good previous assignments on the course website which was much appreciated by students. The Business teacher videoed student oral presentations, replayed short extracts and engineered reflective discussions which illuminated the characteristics of good business presentations.

The most extended treatment of the development of evaluative expertise arose in Sam's teaching of a Year 1 course: Introduction to Architectural Design taken by 65 students divided into six tutor groups of around 11 students per group. Assessment for the course was based on a portfolio of designs for a house in a nearby village, including presentations and iterations of designs. An important aspect of the development of the assessment portfolio was a series of critical reviews, called 'crits', where students present in front of their peers a design project to a jury of teachers and receive comments on their work. There were a number of crit sessions: two crits at an interval of about one month with two tutors providing commentary; and a final review involving a jury of four tutors, including one coming from outside the university. The crit is part of the signature pedagogy of design-based subjects (Schrand \& Eliason, 2012) and mirrors WTP in the discipline as the need to pitch designs is a core element of the architecture profession.

Sam commented on the crit as follows:

All teaching is based on some kind of dialogue. The crit allows it to be personal, it also allows for feedback to be reflective of the students' intentions.

In addition, you are opening it up to an outsider view.

The crit is somewhat different to feedback on work in progress because of the public nature of the dialogue. So the crit is both specific to an individual student and reflective in relation to bringing together wider public ideas about Architecture. A 
challenge for the audience of peers is in picking up messages that may either inform their own work or stimulate their own understandings of the theory and practice of Architecture and its discourses.

Sam highlighted three aspects of quality in architectural design: craft - the quality of the craftsmanship in the designs; contribution, including originality and creativity; and concept as embodied in the overall design process. I asked Sam how students come to develop a sense of quality:

I think it's a balance between rationale and intuition. In some sense it is ruledriven, but you also have to know the limit of those rules. ... I also want them to learn how to strategize the process because the goal is not to produce a great design but to learn how to structure a design process.

I took up a parallel line of inquiry by asking a student (pseudonym Laurence) what he thought the tutors were looking for in terms of quality work:

I think they are looking for consistency throughout the body of work; depth of thought; and craftsmanship, the quality of the drawings. It's also about communication: the clarity of the intentions in your drawings. But having said that, what the tutors are looking for is somewhat unclear to me and sometimes I get disillusioned ... there are an infinite number of permutations. My interpretation was that Laurence was developing a good grasp of what the Architecture teachers were looking for, whilst exhibiting in the final sentence an awareness of the challenges involved. In creative disciplines, such as design subjects, the individual open-ended nature of problems can represent both a source of anxiety and a stimulus for engagement.

I also had discussions with students soon after their crits. Gloria expressed the view that it is important to interact with the tutors and try to justify the design because that is an important part of becoming an architect. Persuasive presentation and the ability to 'sell' your design to a group of observers is a skill which students are trying to develop. She related this to the idea of becoming your own critic:

I need to ask myself how I can make my design better. It is part of learning to be self-critical. ... We learn to be critical from listening to the teachers' analysis and so we can start to see things from another viewpoint. 
In his crit, Yeung dialogued actively with the tutors and strived to justify his design. Afterwards I asked him about this and he commented as follows:

It is difficult to convince the tutors but we should learn to make the judgments and decisions for ourselves. I need to try to convince the tutors even though I know that I may yield to their ideas eventually.

Our observations of crits and interviews with participants led us to infer that learning to be self-critical and making judgments for themselves were major elements of the processes underpinning the critical reviews.

My prior expectation was that normally the development of evaluative expertise would involve some kind of peer feedback so that students might involve themselves in critiquing each other's work. To my initial surprise, despite repeated observations I saw limited interaction between the student presenter and their peers during the crits. Students told me that this is because the crits already take a long time; and it is difficult for peers to provide insightful comments when they are not deeply familiar with a particular design. From my perspective, this initially seemed like a missed opportunity. Through further interviewing and observation, however, I came to understand that peer feedback in a studio-based discipline took a different form than that often seen in a more conventional classroom setting. My interviews and observations indicated that peer feedback arose more informally during work in the studio and was particularly salient in the final review discussed next.

The final review which lasted from first thing in the morning until late at night created a lot of interest and excitement in the studio. Students were walking around examining designs which were displayed on the walls and through models on the floor. Some students were taking photos of the designs and engaging in discussion of aspects that caught their eyes. Ching made a useful summary of this process:

After taking a look at others' drawings and models, I can learn how to tackle some technical problems and it can inspire me to think differently... Everyone's drawings and models are out there, it is faster and easier for you to see how a problem can be dealt with than asking people individually. 
The informal peer interaction and the visual 'on-display' element of the work were particular features of the final review and I return to these issues in the Discussion section.

In sum, students in the Architecture case were involved in the iterative development of a portfolio in which a central feature was regular presentations of their work for critical review. These processes exposed them to dialogues with the teacher which seemed to help them to hone their self-evaluative capacities and develop an evolving sense of quality in architectural design. The public nature of the design studio and the on-display assignments were also a site for spontaneous peer feedback.

\section{Promoting student engagement with feedback}

The five teachers all strived to provide relevant feedback experiences to students. The interplay between feedback dialogues and the development of student evaluative expertise in Architecture is evident from the previous section. In the Geology case, timely feedback on a brief outline was provided at the outset of the group project so as to try to steer students to find a suitable initial topic and path for their project. The History teacher provided feedback on draft individual projects to inform the next stage of student work. The Business teacher engineered in-class feedback dialogues both about the process of learning and in relation to the particular assessment tasks.

In this section, I focus on feedback in the Tort Law class taught by Chris with a class size of 180 students. The assessments for the course were a test (weighting 20\%); a reflective media diary (20\%) focused on analyzing relevant legal issues occurring in the local media; and a final examination (60\%). For the test and the examination, Chris implemented a strategy of 'same day feedback' when there was immediate discussion of a completed assessment task. This takes place on an optional basis in the classroom where the assessment has taken place, with students discussing possible answers to the legal problem they have just attempted. This is also supplemented by same day online discussion. Chris stated the rationale as follows:

Same day feedback is a forum for debate so that learning continues after the assessment. It allows students to engage in a discussion of the assessment problem, clear up misconceptions and reinforce good learning when their focus is greatest. The immediacy of the feedback overcomes a major obstacle 
to learning, delayed or ignored feedback, by providing feedback in a way and at a time when it can be absorbed. A key principle is that the timing of feedback should be as close to the point of submission as possible.

In this quotation, Chris shows awareness of the need to tackle the common failure of students to engage with common forms of post-assignment feedback which are often received several weeks after a task has been completed. The same-day discussion and debate also brings elements of dialogue into the feedback process. Obviously, students do not have an opportunity to revise their answer to the test or exam, but the feedback aims to clarify issues immediately and feed-forward to future related tasks.

Chris also suggests a further rationale as follows:

The in-class or online discussion often uncovers aspects of the question not considered in the marking rubric. This is not surprising as legal problems are by nature complex and open-ended. Students are expressly encouraged to critique the arguments and offer alternative ones which, if adequately supported by cogent legal analysis, can be included in a revised marking rubric.

This brings a collaborative element to the rubric and an additional incentive for student engagement.

In our interviews, students expressed a variety of perspectives on the strategy of same day feedback:

I like the immediate feedback, because the memory is fresh in my mind and I can remember all the details.

I became aware of the depth of other students' answers; it is always good to know how other students think.

When some students have thought of some creative points that the tutors haven't considered, if you can make a good case you can help shape the marking scheme.

It feels a bit like a heart attack because you find out immediately about your answers. 
I felt awful because I missed a lot of points in my answers, but I really appreciate this kind of interactive learning.

I infer that students are generally positive about the immediacy of the teacher feedback, the opportunity to learn from the thinking of their classmates and the potential to inform the marking scheme. This last point seems particularly significant in relation to issues, such as ownership of assessment and the motivational impact this implies. The only somewhat negative finding is signaled by the last two student quotations above: the potential emotional impact of perceiving you have done badly. This discouraged some students from attending the feedback session because it came at the start of an examination week and they were worried that immediate realization of missteps could have a negative impact on future performance in other examinations. Students, and sometimes their teachers, may shy away from critical feedback for fear that it may disrupt emotional equilibrium.

In sum, this vignette exemplifies some of the possibilities in promoting student engagement with feedback through timely dialogue around performance. A particular feature of the dialogue is that it comes immediately after the assessment, so students receive feedback whilst content is fresh in their memory. Perhaps more significantly, students are involved in articulating their answers, receiving feedback from the tutor and trying to justify their own particular stance with the possibility of contributing to shaping the marking scheme. From this I infer that the main benefit of the immediate feedback session is not just the timing but the way that it engages the students in reflective discussion.

\section{Discussion}

This study explored a model of three interlocking learning-oriented assessment principles in the practices of a sample of award-winning teachers. The integrated nature of the model suggests that in any particular case one or more of its principles may emerge as more prominent and this has been illustrated through three examples in the context of different disciplines. In the History case, the design and implementation of learning-oriented assessment tasks was particularly salient, whereas the other two elements were present but less prominent. In the Architecture case, there was a strong interplay between the portfolio assessment task, the 
development of evaluative expertise and engagement with feedback. In the Law case, the chosen vignette focused on engagement with feedback through timely discussion of an assessment task involving legal problems, whereas the development of student evaluative expertise is less explicit or observable.

The assessment task design and implementation in History focused on a series of tasks which involved students in WTP in the discipline through exploring how history is presented in a site, such as a museum; the relationship between the past and the present; and how history relates to students' own individual lives. Similar to the findings of Anderson and Hounsell (2007) the design of teaching, learning and assessment activities was crafted to draw students into performing historical ways of thinking and acting. A contrasting finding was that Anderson and Hounsell (2007) found that university assessment regulations or established departmental patterns of assessment limited teachers' freedom to create assignments that would be congruent with disciplinary practices, whereas this did not occur in the current study. I suggest that a possible by-product of gaining a teaching award or a characteristic of some award-winning teachers may be a confidence and determination to overcome contextual or logistical barriers in a quest to do what they think will impact positively on their students.

The processes encouraging the development of students' evaluative expertise have been highlighted through exploring critical reviews in Architecture. This case provides evidence from a studio-based discipline to add weight to the conceptual insights of Sadler: activities such as critical reviews provide students with opportunities to develop a sense of quality that begins to approximate the connoisseurship of the expert. Through these processes, students seemed to be learning to be self-critical and to self-evaluate their work pro-actively. The Architecture case also illustrates Hounsell's notion of on-display assignments. The public nature of an assessment event, such as a crit, can bring transparency into assessment by exemplifying the kind of criteria and standards which are being applied; and provide potential for students to learn from peers' presentations and related teacher feedback. Although there was little peer input during the formal teacher-led crit sessions, peer interaction was particularly evident in the informal discussions around the displays during the final review process. The extent to which 
useful peer feedback arises spontaneously or needs to be engineered by teachers within classroom time may vary across disciplines and across classes. These notions of 'spontaneous' and 'engineered' peer feedback may merit further consideration.

I suggested at the outset that an aspect of learning-oriented assessment is to alleviate the double duty phenomenon by focusing summative assessment as well as formative assessment on promoting student learning. The Architecture case provides some support for that position in that the portfolio represented both a final summative product and formative processes of iteration, feedback and self-evaluation underpinning its development. This resonates with the position of Orr and Bloxham (2012) who assert that in Art and Design students' development work and final work are assessed in their totality, challenging the notion of the separation of formative and summative assessment. This scope for interweaving of teaching, learning and assessment is something teachers in other contexts or disciplines might strive to emulate.

Student engagement with feedback was particularly a feature of the Architecture and Law cases. From the Architecture case, I infer two useful principles of effective feedback processes: they are dialogic rather than uni-directional; and within class rather than end-loaded. Importantly, the crits acted both as a means of feedback and a forum for developing student understandings of the nature of quality work. The same day feedback example in Law focused on engaging students in prompt dialogues around quality legal analysis immediately after an assessment, despite the constraints of a large class size and limited time available. This Law vignette also provides a flavor of some key elements of feedback processes (cf. Evans, 2013), such as timeliness; interplay of teacher commentary and student expression of views; and the affective impact of feedback.

\section{Conclusion}

I have discussed three principles of learning-oriented assessment in relation to a model which represents what I see as the essence of assessment practice focused on developing productive student learning processes. The model represents a coherent approach in that it views assessment tasks, students' evaluative expertise and engagement with feedback not as isolated aspects but as parts of an integrated whole. 
This is particularly well illustrated by the Architecture case in which there was coherence between the portfolio assessment task; and the interplay between student self-evaluation and dialogic feedback stimulated by the processes of critical reviews of students' designs. Facilitating factors in that case were the intensive teacher-student interactions and the small size of the tutorial group. The large classes in History and Law did not, however, represent insurmountable barriers to varied learning-oriented assessment practices, suggesting that the determination and commitment of teachers can tackle some of the challenges in developing effective assessment processes.

The model itself and the interplay between its different elements invite further exploration. I end with two related issues for further research. What are the main inter-disciplinary commonalities or differences in the principles underpinning the design and implementation of learning-oriented assessment tasks? Under what circumstances does feedback open up or close down opportunities for students to develop their own evaluative expertise?

Acknowledgement. This research is funded by the Research Grants Council of Hong Kong: HKU 740812H

\section{References}

Anderson, C. \& Hounsell, D. (2007). Knowledge practices: 'doing the subject' in undergraduate courses. The Curriculum Journal, 18(4), 463-478.

Boud, D. (2000). Sustainable assessment: Rethinking assessment for the learning society. Studies in Continuing Education, 22(2), 151-167.

Boud, D. \& Falchikov, N. (2007). Developing assessment for informing judgment. In D. Boud \& N. Falchikov (Eds.), Rethinking assessment in higher education (pp. 181-197). London: Routledge.

Boud, D. \& Molloy, E. (2013). Rethinking models of feedback for learning: the challenge of design. Assessment and Evaluation in Higher Education, 38(6), 698712.

Carless, D. (2007). Learning-oriented assessment: Conceptual basis and practical implications. Innovations in Education and Teaching International, 44(1), 57-66.

Carless, D. (2015). Excellence in University Assessment: Learning from awardwinning teaching. London: Routledge. 
Carless, D., Salter, D., Yang, M., \& Lam, J. (2011). Developing sustainable feedback practices. Studies in Higher Education, 36 (4) 395-407.

Evans, C. (2013). Making sense of assessment feedback in higher education. Review of Educational Research, 83(1), 70-120.

Gibbs, G. (2006). How assessment frames student learning. In C. Bryan \& K. Clegg (Eds.), Innovative assessment in higher education (pp. 23-36). London: Routledge.

Hernandez, R. (2012). Does continuous assessment in higher education support student learning? Higher Education, 64, 489-502.

Hounsell, D. (2003). Student feedback, learning and development. In M. Slowey \& D. Watson (Eds.), Higher Education and the Lifecourse (pp. 67-78). Maidenhead: Society for Research into Higher Education.

James, D. (2014). Investigating the curriculum through assessment practice in higher education: The value of a 'learning cultures' approach. Higher Education, 67, 155-169.

McCune, V. \& Hounsell, D. (2005). The development of students' ways of thinking and practising in three final-year biology courses. Higher Education, 49, 255289.

Nicol, D. (2010). From monologue to dialogue: Improving written feedback processes in mass higher education. Assessment and Evaluation in Higher Education, 35(5), 501-517.

Nicol, D., \& D. Macfarlane-Dick. (2006). Formative assessment and self-regulated learning: A model and seven principles of good feedback practice. Studies in Higher Education, 31(2), 199-218.

Norton, L., Norton, B. \& Shannon, L. (2013). Revitalising assessment design: What is holding new lecturers back? Higher Education, 66, 233-251.

Orr, S. \& Bloxham, S. (2012). Making judgments about students making work: Lecturers' assessment practices in art and design. Arts and Humanities in Higher Education, 12, 2-3, 234-253.

Prosser, M. (2013). The Four-Year Degree in Hong Kong: An opportunity for quality enhancement. In R. Land \& G. Gordon (Eds.), Enhancing quality in higher education (pp. 201-212). London: Routledge.

Sadler, D. R. (1989). Formative assessment and the design of instructional systems, Instructional Science, 18, 119-144. 
Sadler, D. R. (2010). Beyond feedback: Developing student capability in complex appraisal. Assessment and Evaluation in Higher Education, 35(5), 535-550.

Sambell, K., McDowell, L. \& Montgomery, C. (2013). Assessment for learning in higher education. London: Routledge.

Schrand, T. \& Eliason, J. (2012). Feedback practices and signature pedagogies: What can liberal arts learn from the design critique? Teaching in Higher Education, 17(1), 51-62. 